\title{
A PAZ REJEITADA: UMA REFLEXÃO SOBRE DEVER DE MEMÓRIA E ESQUECIMENTO NO ACORDO DE PAZ COLOMBIANO
}

\author{
THE REJECTED PEACE: A REFLECTION ON THE DUTY TO \\ REMEMBER AND FORGETFULNESS IN THE COLOMBIAN PEACE \\ AGREEMENT
}

Fabiana Santos Dantas

Universidade Federal de Pernambuco (UFPE) - (Recife, PE, Brasil)

Recebimento: 20 fev. 2017

Aceitação: 18 jul. 2017

\begin{abstract}
Como citar este artigo / How to cite this article (informe a data atual de acesso / inform the current date of access):
DANTAS, Fabiana Santos. A paz rejeitada: uma reflexão sobre dever de memória e esquecimento no acordo de paz colombiano. Revista da Faculdade de Direito UFPR, Curitiba, PR, Brasil, v. 62, n. 2, p. 227 - 244, maio/ago. 2017. ISSN 2236-7284. Disponível em: <http://revistas.ufpr.br/direito/article/view/50773>. Acesso em: 28 ago. 2017. DOI: http://dx.doi.org/10.5380/rfdufpr.v62i2.50773.
\end{abstract}

A memória é o treinamento daqueles que querem fazer o próprio futuro. (CARRETERO, 2010, p. 233)

\section{RESUMO}

O objetivo do presente artigo é refletir sobre o dever de memória como um dos possíveis fatores que levaram à negativa da sociedade colombiana à primeira proposta de acordo de paz entre o governo e as FARC. O resultado do referendo representa apenas o não a uma proposta ou a uma tradicional estratégia de esquecimento que marca as transições latino-americanas? Investigar o processo de negociação de cessação do conflito armado na Colômbia contribuirá para o entendimento dos mecanismos de construção e afirmação dessa memória coletiva traumática, bem como das possibilidades de implementação de uma justiça transicional efetiva. O legado da paz rejeitada poderá, em médio e longo prazo, ser revelado como um importante passo na consolidação da democracia e da paz verdadeira, duradoura e estável para a sociedade colombiana. A metodologia da pesquisa consistiu em pesquisa bibliográfica, realizada por meio da análise de livros, artigos científicos, de revista e de jornal referidos e de pesquisa documental quanto à legislação específica e documentos produzidos pelo governo colombiano.

\section{PALAVRAS-CHAVE}

Memória. Direitos humanos. Justiça de transição.

\begin{abstract}
The aim of this paper is to reflect on the duty to remember as one among many factors that motivated the rejection of the first proposal of a peace agreement between the Colombian government and the FARC. Is this result just a negative response to an agreement, or is it a negation of a traditional strategy of oblivion so common in Latin American transitions? Reflecting on this peace negotiation process to end the conflict in Colombia would lead to a better understanding about the mechanisms of construction and affirmation of this traumatic collective memory, as well as about the possibility of
\end{abstract}


implementation of an effective transitional justice. The legacy of the "rejected peace" would be an important step in the consolidation of democracy and a true, stable and durable peace for the Colombian society. The research methodology consisted of a literature search, through the analysis of books, scientific articles from magazines and peer-reviewed journals, as well as documental research relative to specific legislation and documents produced by the Colombian government.

\section{KEYWORDS}

Memory. Human rights. Transitional justice.

\section{INTRODUÇÃO}

A premissa de que a paz é boa, e sempre melhor que qualquer guerra, parece ser compatível com a representação que dela se faz, como meio e fim da superação de conflitos. Porém, e se a proposta viola o sentimento de justiça, desconsidera feridas e um passado doloroso que não foi superado?

O "no" colombiano ao acordo de paz entre governo e as FARC no referendo de dois de outubro de 2016, ainda que por uma pequena margem de votos, foi considerado surpreendente e, em certa medida, injustificado, porque perpetuaria uma guerra que já durava 52 anos. A divisão da sociedade em um tema tão polêmico era esperada, mas o resultado do referendo, assim como ocorreu no Brexit, contrariou o senso comum, as expectativas governamentais e de um público com experiência e percepção diversas dos votantes que vivenciaram o trauma.

O passado na América Latina é marcado pela violência e deve ser constantemente amenizado para não perturbar o frágil equilíbrio social. Sob a ideia de “evitar excessos ideológicos”, os Estados latino-americanos sempre buscam barganhar com o passado, utilizando a técnica conciliatória e redentora do esquecimento, especialmente quando se faz necessário enfrentar temas políticos ainda vívidos e traumáticos. Seria o “no” uma reação às estratégias de esquecimento tão inerentes ao fazer político latino-americano?

O objetivo do presente artigo é refletir sobre as razões políticas, legais e sociais que levaram a sociedade colombiana a não referendar o acordo de paz negociado entre o governo colombiano e as FARC, do ponto de vista da construção de uma memória coletiva sobre a experiência desse trauma, com foco no contexto latino-americano. A reflexão foi dividida em três tópicos, sendo o primeiro uma análise panorâmica das estratégias de esquecimento identificadas como violadoras do direito à memória, o segundo uma reflexão sobre o significado memorial do resultado do referendo, e o terceiro uma análise do texto do acordo aprovado, com ênfase nas questões de reparação e reconhecimento do direito à memória individual e coletiva. 
A metodologia utilizada consistiu em pesquisa bibliográfica, realizada por meio da análise e fichamento crítico dos livros, artigos científicos e documentos referidos ao final, além da pesquisa documental sobre leis e outros instrumentos normativos, e também de um breve estudo comparativo entre o texto do primeiro acordo de paz rejeitado e o segundo, com o objetivo de demonstrar a utilização das estratégias do esquecimento.

\section{AS ESTRATÉGIAS DO ESQUECIMENTO E A IMPOSSIBILIDADE MOMENTÂNEA DO PERDÃO: APROXIMAÇÕES DO ACORDO DE PAZ REJEITADO NA COLÔMBIA}

O século XX foi um momento conturbado da história política latino-americana, quando vários Estados atravessaram momentos ditatoriais intercalados por efêmeros momentos de democracia, marcando indelevelmente a memória coletiva das passadas, presentes e futuras gerações de cidadãos.

Na América do Sul, diversos regimes ditatoriais se estabeleceram entre as décadas de 1960 e 1980, com características bem semelhantes, podendo ser citados como exemplos os do Brasil (19611988), do Chile (1973-1990), da Argentina (1966-1983), do Paraguai (década de 1950 a 1989, com a deposição de Stroessner) e do Uruguai (1973-1984). Em comum, esses regimes ditatoriais iniciaram com golpes de Estado, portanto se trata de governos ilegítimos do ponto de vista democrático, tendentes ao totalitarismo, e que adotaram uma prática sistemática de violação dos direitos humanos, com a perseguição dos opositores, torturas, homicídios e prisões ilegais.

A transição desses períodos em que havia conflitos e violações de direitos humanos para um regime democrático compreende um conjunto de transformações institucionais, incluindo mudanças de práticas, da cultura organizacional, revisão e ressignificação do passado. Na América Latina tanto a memória coletiva do período quanto a da transição foram objeto de uma política conciliatória baseada no esquecimento, que em geral contempla seis elementos bem caracterizados: a produção da memória oficial sem os fatos inadequados, a concessão de anistias, a fabricação do consenso pelo discurso da superação das ideologias, o simples silêncio sobre fatos conflituosos, a busca da reconciliação nacional e as comemorações de datas cívicas criadas para celebrar determinada versão histórica (DANTAS, 2010, p. 56).

Embora a Colômbia não tenha experimentado uma ditadura militar nos moldes de outros Estados latino-americanos nas décadas de 1960 a 1980, sendo formalmente identificada uma experiência semelhante entre os anos de 1953-1957, isso não significa que houve a consolidação de um regime democrático sólido, com efetivo respeito aos direitos humanos e fundamentais. Ao 
contrário, a conversão de medidas excepcionais, como o estado de sítio, em forma ordinária de governar, e a adoção de um Estatuto de Seguridad repressivo representaram a intensificação de uma violência generalizada e, em certa medida, legitimaram a perseguição política e a criminalização das demandas por direitos humanos.

A sociedade colombiana está historicamente imersa em um contexto de violência, que provém de variadas fontes e possui eixos econômicos, culturais e políticos. Além da violência sistemática contra os direitos dos cidadãos, havia também uma violência que minava as instituições, tais como o Poder Legislativo e o Poder Judiciário, dos quais duzentos e noventa servidores foram assassinados no exercício de funções judiciais, no período de 1979 a 1991, e um permanente estado de ameaça (CENTRO NACIONAL DE MEMORIA HISTÓRICA, 2016, p. 16).

Esse contexto de violência justificou a coercitividade estatal na Colômbia como a única e mais eficiente forma de garantir a ordem e a paz social, à semelhança do que ocorreu em outros Estados sul-americanos nesse período, seja porque a sociedade experimentava um desequilíbrio econômico e políticos crônicos, seja pela indicação de um "inimigo" que deveria ser combatido com força e vigor (JELIN, 2009, p. 126), que foi assim identificado:

Un elemento de análisis que debe tomarse en cuenta en el contexto descrito es la influencia de la Doctrina de la Seguridad Nacional en las Fuerzas Militares, según la cual "la guerrilla [era] apenas un apéndice de la subversión” (Zafra, 1987, página 39). Por lo tanto, para el Estado el mayor peligro provenía de la denominada guerra política, entendida como el conjunto de acciones subversivas orientadas a obtener la simpatía y apoyo de las masas. El derecho a la justicia como garantía de no repetición Asociada a esta doctrina se construyó la noción de enemigo interno, que fue precisamente la que terminó definiendo el blanco de la guerra sucia que se desató a finales de los años ochenta. Esta guerra sucia se dio en un contexto de abierto reconocimiento de la legitimidad de la conformación de grupos de autodefensa por parte de altos miembros del Estado, así como de la existencia de un marco legal que permitía la participación de civiles armados en acciones militares (CENTRO NACIONAL DE MEMORIA HISTÓRICA, 2016, p. 18).

O combate ao inimigo interno que legitimou o uso da força pelo Estado colombiano, em resposta ao anseio popular pela paz e pela ordem, levou-o a praticar atos de violência contra os seus próprios cidadãos, tais como detenções arbitrárias, tortura e abuso do Estado de exceção.

As Fuerzas Armadas Revolucionarias de Colombia eram um dos inimigos a serem combatidos com força pelo Estado e essa foi a versão consolidada e transmitida sob a forma de memória coletiva aos cidadãos. A construção de uma memória oficial de um período, estruturada por meio de uma política específica, consistente na produção de discursos organizados em torno de acontecimentos e personagens, concretizados em monumentos, celebrações e instituições, é fundamental para estabelecer o sentido das ações. Os grandes desafios dessa versão oficial são a credibilidade, a aceitação e a sua organização, considerando a necessidade de sempre manter um 
discurso coerente sobre o passado ideologicamente reconstruído, para evitar rupturas de aceitação pela sociedade, o que afetaria a sua identidade (POLLAK, 1989, p. 10).

Portanto, deve-se indagar: Qual é a representação que a população colombiana faz das FARC? Seria um movimento político legítimo, de contestação, ou apenas uma forma de crime organizado financiado pelo e patrocinador do tráfico de drogas, responsável por desaparecimentos forçados, que punha em risco a estabilidade política e institucional do Estado?

Por outro lado, criado o fato, é preciso incutir na memória coletiva a versão correta que se quer legar, inventando datas celebrativas adequadas à construção do sentido e à ligação entre o passado e o presente por meio da comemoração. O calendário oficial é um espaço privilegiado para construir e veicular os símbolos da comunidade (JELIN, 2009, p. 128) e, no caso da Colômbia, foi escolhido o dia 30 de agosto como nova data significativa para relembrar os detidos e desaparecidos, como estabelece o artigo 14 da Ley $n^{\circ}$ 1.408/2010:

Art. 14: La memoria histórica de las víctimas del conflicto colombiano desaparecidas forzadamente será objeto de conmemoración la última semana de mayo, en el marco de la Semana de los Detenidos - Desaparecidos, y el treinta (30) de agosto, Día Internacional de los Desaparecidos. Los establecimientos educativos públicos y privados y las autoridades nacionales, departamentales y municipales rendirán homenaje a estas víctimas esta semana con la realización de foros, conferencias, talleres y jornadas de reflexión referentes al derecho a la memoria, a la verdad, a la vida y al respeto por los derechos humanos.

A busca da sociedade colombiana pela efetivação do "Direito à Justiça” aprofundou a percepção da necessidade de dar reconhecimento às vítimas, de não as esquecer, de fazer justiça para elas. Como, então, compatibilizar essa necessidade e essas percepções com uma proposta de concessão de perdão (anistia ou indulto) aos inimigos?

A reconciliação, nesse caso, passa necessariamente pela desconstrução das representações, conceitos e preconceitos, que permitam estabelecer um consenso sobre o processo de paz. A fabricação desse consenso pode ser um mecanismo de esquecimento, quando realizado por meio do discurso de superação das ideologias, com a explícita intenção de demonstrar que a sociedade “superou” as divergências que levaram à instabilidade política que culminou no período de exceção. Ao deixar no passado essas divergências e esses conflitos, na verdade a sociedade estaria apta à reconciliação nacional, que, pelo seu caráter pacificador, tem sido a grande justificativa das anistias concedidas no contexto sul-americano.

O processo de negociação da paz entre o governo colombiano e as FARC, e a sua fracassada tentativa de validação por meio do referendo em 2016, podem ser interpretados como uma estratégia de esquecimento baseada em quatro práticas distintas: o silêncio, a minimização de conflitos, a concessão de anistias e a busca da reconciliação nacional pela superação das “divergências” anteriores 
(DANTAS, 2014). A questão que se impõe passa a ser se a rejeição do acordo de paz, ou da forma de negociá-lo e concebê-lo, pode ser interpretada como uma reação à tradicional estratégia de esquecimento que marca as transições latino-americanas.

Para essa reflexão, o ponto $\mathrm{n}^{0} 5$ - Acuerdo sobre las víctimas del conflicto - é especialmente elucidativo, uma vez que traz os elementos básicos da denominada "Justiça de Transição” como princípios: reconhecimento das vítimas e das responsabilidades, esclarecimento da verdade, participação e reparação das vítimas, reconciliação e garantia de não repetição.

A inclusão, nesse capítulo, dos dispositivos sobre a anistia e o indulto demonstra o íntimo vínculo entre reparação e reconciliação, com o fato de que há condutas que não podem ser anistiadas e indultadas, ou esquecidas. A anistia em si, como meio de pacificar e reconciliar a sociedade, só pode ser legitimamente utilizada quando não impuser o esquecimento e a escamoteação dos fatos. Como bem destacam Flávia Piovesan e Hélio Bicudo (2006), refletindo sobre o caso brasileiro:

O direito à verdade assegura o direito à construção da identidade, da história e da memória coletiva. Serve a um duplo propósito: proteger o direito à memória das vítimas e confiar às gerações futuras a responsabilidade de prevenir a repetição de tais práticas. Sob a ótica republicana e democrática, a releitura da Lei de Anistia e o direito à verdade rompem com o pacto do silêncio e com uma injustiça continuada. Lançam luzes à dimensão sombria de nossa história, na defesa dos direitos à justiça, à verdade e à memória individual e coletiva.

Em síntese, a opção pela reconciliação e pela pacificação nacional não deve ser uma decisão administrativa, e muito menos o acordo rejeitado poderia ser considerado a última e final versão de um processo que não se exaure, evidentemente, nem com sua aprovação em 2016 e nem mesmo pela sua execução. Não há nenhum óbice para a revisão, ressignificação e reconstrução interpretativa do passado: mesmo que determinada geração acordasse com uma suposta reconciliação baseada no esquecimento, tal fato não impediria que as gerações futuras discordassem de tal procedimento e tirassem dessa situação lições valiosas para o seu presente e seu futuro, até como forma de combater as estruturas autoritárias e violentas ainda remanescentes.

\section{O “NO” COMO DEVER DE LEMBRAR: TRANSIÇÃO COMO REPARAÇÃO E SUPERAÇÃO}

Existem muitos fatores para o resultado negativo no referendo convocado para a legitimação do acordo de paz a ser celebrado entre o governo colombiano e as FARC, inclusive dúvidas quanto à lisura do pleito, quanto à sua baixa representatividade ${ }^{1}$ devido à escassa participação da população,

\footnotetext{
${ }^{1} \mathrm{O}$ resultado foi aferido com 37\% de votos e 63\% de abstenções (PLEBISCITO..., 2016).
} 
quanto à motivação política dos opositores, que também pretendem minar a governabilidade para manter o status quo, benéfico a determinados setores tradicionais da economia. O furacão Matthew, razões religiosas (MARCOS, 2016), e mesmo a descrença nos inúmeros processos anteriores de negociação da paz que se mostraram frustrados, possivelmente levaram o governo a nomear a nova iniciativa como "acordo final para a terminação do conflito e a construção de uma paz estável e duradoura”, para conferir-lhe maior credibilidade.

As causas são complexas, mas, neste artigo, o objetivo é refletir sobre um aspecto memorial desse "não". Como visto no item anterior, a sociedade colombiana experimentou o trauma da violência sistemática durante décadas, e o histórico da construção da defesa dos direitos humanos exigiu a criação de ferramentas, procedimentos, comemorações e mobilizações que deixaram marcas na memória coletiva.

Legitimar o acordo de paz seria esquecer desse processo histórico da conquista de direitos? Seria uma injustiça com os desaparecidos e com as vítimas? Seria premiar aqueles representados como inimigos?

Ora, lembrar e esquecer são etapas de um mesmo processo, e muitos fatores contribuem para determinar o esquecimento de fatos, sendo especialmente importantes a retração do espaço de discussão pública (pelo medo, falta de segurança, repressão) e o empobrecimento das estruturas comunicativas habituais com a segmentação dos espaços de encontro e conversação, pois onde não existe o vínculo social forte não há suporte e nem material para a memória coletiva (LECHNER; GÜELL, 2006, p. 33). O limite do exercício legítimo do esquecimento é quando se torna violador da moral e da consciência.

A sociedade e os indivíduos que não têm acesso à verdade e experimentam a impunidade propiciada pelo esquecimento acabam por ver prejudicada a sua capacidade de percepção, de distinguir entre o certo e o errado, gerando a insegurança, incerteza, ansiedade e a perda da confiança, que destroem a solidariedade social (BAEZA, 2005).

A tortura, o cárcere, o desaparecimento forçado, o assassinato e a perseguição por razões políticas deixam marcas indeléveis nas vítimas, nos familiares e nas instituições, e seus efeitos não se esgotam na geração que sofreu a experiência traumática, transmitindo-se às próximas gerações, e acabam por afetar o bem-estar e a identidade cívica dos indivíduos, possuindo um efeito desagregador que afeta a coesão social (MIÑARRO; MORANDI, 2009, p. 441).

É preciso cobrar responsabilidades: o esquecimento não pode ser um artifício para a impunidade e nem uma forma de negligência que permita que velhos erros voltem a prejudicar a sociedade (NOITE..., 2006). Não há dúvidas de que o direito ao esquecimento é uma chance para 
recomeçar: a questão é se será aproveitada moral ou amoralmente, com ou sem concordância histórica (WEINRICH, 2001, p. 232). Assim, como afirma Filloux (1959, p. 73):

O esquecimento é dotado de um caráter teleológico, não é o avesso da memória, mas um aspecto indireto dessa mesma memória, tem uma função positiva, e essa forma da sabedoria humana, que chamamos de experiência, não consiste menos em expulsar do espírito os pormenores inúteis, insignificantes e vãos, do que guardar os que comportam um ensinamento ou uma lição.

A superação do trauma coletivo está diretamente ligada a uma obrigação de recordar, para evitar que o esquecimento seja indevidamente utilizado para impor mais sofrimento às vítimas. Esse dever de memória consiste em tornar presentes os fatos dolorosos da sociedade por meio da recordação contínua, para possibilitar o aperfeiçoamento das instituições e da vida social, e também manter a sociedade e os indivíduos vigilantes para resistirem mediante a lembrança.

Diante disso, como encarar a proposta de anistia, um elemento da estratégia do esquecimento comum aos países latino-americanos, e que muitas vezes assumiu a feição de autoanistias em benefício aos agentes do Estado que perpetraram violações aos direitos humanos?

A transição para democracia nesses Estados foi feita com base no silêncio e no esquecimento que, como bem destaca Vinyes (2009, p. 26-30), não decorreu de um pacto social, mas de uma decisão administrativa e de um processo institucional para superar os conflitos transicionais, tendo a “reconciliação como objetivo, o consenso como programa e o esquecimento como instrumento".

Por uma questão de justiça, e por princípio, a anistia não pode ser uma forma de "impunidade equitativa” cujos efeitos serão remediados pelo passar tranquilo das décadas. É preciso refletir sobre o real significado da anistia, e se ela é um meio cômodo de evitar a assunção dos efeitos éticos, psicológicos, jurídicos e econômicos das responsabilidades políticas daqueles que atentaram contra a democracia. O sentimento de urgência e necessidade de invalidação das anistias abusivas baseia-se na convicção de que a construção de uma democracia real e sólida, com o desenvolvimento econômico e social, só será possível se for fundada na verdade histórica, porque não se constrói uma sociedade realmente democrática sobre mentiras.

Essa reflexão levou à busca da invalidação das leis de anistia na Argentina, no Chile, no Brasil e no Uruguai, com consequências e ritmos diferentes. Na Argentina a Suprema Corte analisou a causa $\mathrm{n}^{\circ}$ 17.768-S.1767.XXXXVIII ${ }^{2}$, em que declarou por maioria a inconstitucionalidade da Ley

\footnotetext{
${ }^{2}$ Do original em espanhol: “Aún las leyes de amnistía tienen un límite moral, y está dado por la imposibilidad de amnistiar delitos de lesa humanidad, porque si se pretende forzar a 'olvidar' y a perdonar los agravios proferidos a los significados profundos de la concepción humana, si los delitos atroces quedan impunes, la sociedad no tiene un futuro promisorio porque sus bases morales estarán contaminadas” (Voto do Dr. Ricardo Luis Lorenzetti).
} 
$\mathrm{n}^{\circ} 23.492^{3}$, denominada “Punto final”. Com a invalidação das normas de anistia e dos atos de indulto torna-se juridicamente viável responsabilizar os agentes e o próprio Estado pelas violações de direitos humanos perpetradas contra os argentinos e estrangeiros considerados opositores do regime.

Não é admissível, que sob o pretexto da reconciliação nacional, sejam desconsiderados os relatos de dor pública das vítimas, dos familiares e daqueles que, mesmo sem essa experiência próxima, por laços de solidariedade intergeracional sentem-se também violados em seu direito fundamental à memória individual e coletiva. Não é admissível que as vítimas sejam obrigadas a conviver, às vezes no mesmo círculo social e funcional que os seus algozes, ou que os vejam ainda representar a vontade do Estado.

\section{3 “NO”, COMO “NO OLVIDAR Y NO REPETIR"}

O resultado do referendo, em última instância, não negou a possibilidade da paz, mas de uma forma de paz que talvez não fosse compatível com os anseios dos votantes. O acordo rejeitado foi reformulado, sofreu diversas alterações e sua aprovação final deu-se pelo Poder Legislativo colombiano, desta vez sem a oitiva da população.

Sem um novo referendo, circunstância que trouxe questionamentos pontuais sobre a sua legitimação, a representação indireta pelo Congresso Nacional acolheu alguns dos argumentos contrários para alterar os termos do acordo. Sem dúvida, a rejeição propiciou um maior diálogo e o aperfeiçoamento do texto, acrescentando mais uma etapa no processo de cura e superação do conflito, que apenas se inicia.

Há um longo caminho a ser percorrido até a pacificação possível da sociedade colombiana, e o acordo servirá de diretriz. Se eficazmente executada, essa promessa conseguirá atacar algumas das principais causas do conflito, e não apenas os seus sintomas, contribuindo para transformar estruturalmente a sua realidade econômica, social e cultural.

Do ponto de vista da efetivação do direito à memória e à justiça, o ponto 5 concentra medidas de satisfação e prevenção consagradas como remédios úteis para a reparação de graves violações de direitos humanos, tais como previstas na Resolução nº 60/147 da Organização das Nações Unidas (2005), em especial no item 22. Por exemplo:

a) Medidas efetivas para cessar a continuidade das violações de direitos humanos, previstas no ponto 3, basicamente como o acordo bilateral de cessar-fogo definitivo, um cronograma

\footnotetext{
${ }^{3}$ Sancionada em 23/12/86, promulgada em 24/12/86 e publicada no Boletín Oficial em 29/12/86.
} 
de deixação de armas e um sistema material e imaterial de proteção, que garanta a reintegração e a não estigmatização dos cidadãos reabilitandos.

b) Proceder à apuração dos fatos, consagrando o direito à verdade. O ponto 5 prevê a instalação de uma comissão da verdade, como um órgão temporário e de caráter extrajudicial, componente do Sistema Integral de Verdad, Justicia, Reparación e no Repetición, com a missão de esclarecer os fatos e as violações, oferecendo explicação ampla sobre as complexidades do conflito, promover o reconhecimento das vítimas, das responsabilidades daqueles que participaram e fomentar a convivência.

Os temas históricos silenciados tornam-se alvo de curiosidade recorrente, sempre se encontrando formas alternativas de explorar, percorrer e conhecer o que foi escondido (KAUFMAN, 2006, p. 56).

O direito fundamental à memória condensa essas reivindicações, correspondendo à necessidade individual e coletiva de afirmação e conhecimento atuais do passado, e sua eficácia é manifestada em posições jurídicas de primeira, segunda e terceira dimensões: no aspecto individual, abrange a memória dos vivos e dos mortos, enquanto que na dimensão prestacional, envolve o direito a participar da elaboração de políticas públicas para a conservação do patrimônio cultural e à utilização dos bens públicos que o constituem. A dimensão transpessoal compõe-se da manifestação como direito de terceira e de quarta dimensão, abrangendo sujeitos atuais e as gerações futuras, que são ligados por laços de solidariedade intergeracional (DANTAS, 2010).

Cada uma dessas posições jurídicas tem sido objeto de demandas sociais e jurídicas nas últimas décadas, o que demonstra a existência de um processo em curso de reconstrução e ressignificação da memória coletiva, que geralmente inicia com a denúncia da repressão estatal, dando visibilidade aos presos políticos, aos mortos e desaparecidos (PASTORIZA, 2009, p. 294). A memória individual dos vivos e dos mortos foi o motor para a revisão da memória coletiva desse período, que vem sendo efetivada principalmente por instâncias institucionais como as comissões da verdade, que tradicionalmente têm por função explicar as causas de instalação de regimes ditatoriais e o papel de instituições e dos atores no período (PASTORIZA, 2009, p. 303). A natureza precípua das comissões da verdade é ser modo de produção de conhecimento e de inscrição de uma nova versão dos fatos (CRENZEL, 2009, p. 360).

As consequências dessa busca pela veracidade e integridade do passado podem ser preventivas ou repressivas, quando viabilizam a punição dos culpados pelas violações de direitos fundamentais, que traz inerente a necessidade de não repetição, sendo oportuna a reflexão de Pastoriza (2009, p. 301): 
[...] la memoria del terrorismo de Estado, signada por la desaparición, se forjó en el deseo del 'Nunca Más', aferrada a la esperanza de que la fuerza ética del recuerdo colectivo de crímenes que lesionaron la condición humana fijara un punto de no retroceso, una barrera a la posibilidad de reiteración.

c) A busca pelos desaparecidos e recuperação dos corpos para identificação e execução dos devidos ritos funerários, em concordância com os desejos das vítimas ou com as práticas culturais dos familiares e da comunidade. O item 5.1, $b$, do acordo prevê uma unidade especial de caráter humanitário e extrajudicial, com o objetivo de realizar a busca e a identificação das pessoas desaparecidas, bem como de realizar a localização e entrega digna de restos mortais. A citada Resolução n ${ }^{\circ}$ 60/147, item 22, c, prevê também, como medida satisfativa, a identificação das crianças sequestradas, não sendo identificada diretriz específica no acordo, nem relatos de adoções forçadas.

Assim como a representação do inimigo é fundamental para dar contexto ao resultado do referendo e do acordo, o mesmo ocorre com os desaparecidos. Buscar apenas "vítimas” pode significar a errônea identificação dos motivos que levaram à desaparição forçada desses cidadãos, porque o processo de vitimização separa o status de vítima das causas políticas que o criaram (VINYES, 2009, p. 56). Encontrando-se vítimas, perde-se a oportunidade de entender histórica e politicamente como antagonismos políticos e ideológicos derivaram em conflitos, o que afetará a forma como os mortos, desaparecidos e sobreviventes serão lembrados e interpretadas as suas ações.

d) Declaração formal restaurando a dignidade e o direito das vítimas, e de seus entes próximos, que pode ter origem judicial ou extrajudicial. No acordo de paz o reconhecimento das vítimas e a satisfação dos seus direitos aparece como princípio e como objetivo (item 5.1, a) a ser alcançado por meio de uma combinação de medidas de caráter judicial e extrajudicial, de reparação, restituição e satisfação.

Embora existam medidas previstas em normas internacionais, não há uma fórmula geral, e cada conflito vai desenhar as medidas específicas que serão as mais efetivas para a reparação das vítimas.

e) Pedido de desculpas público, incluindo o reconhecimento dos fatos e a aceitação da responsabilidade. A responsabilização é um princípio e um objetivo previstos no item 5 (5.1, a), sob a denominação de "rendición de cuentas", manifestando-se o propósito de não se intercambiar impunidades.

f) A previsão de sanções para os participantes do conflito, e de uma jurisdição especial para julgar os crimes cometidos em sua razão, com especial atenção para as regras de conexão relativas ao narcotráfico.

g) Comemorações e tributos às vítimas, previstos como medidas simbólicas a serem 
especificadas no plano de reparação coletiva com enfoque territorial (item 5, 5.1.3.3.2), compreendidas como medidas dirigidas às vítimas diretas, individuais e coletivas, tais como a dignificação da memória, homenagens, comemorações e monumentos (arquitetura comemorativa).

A memória pode ser transmitida por diversos meios materiais e imateriais, tais como monumentos, textos escritos, oralmente, por meio de cerimônias, celebrações e datas festivas (dias memoriais), costumes, rituais. As comemorações não celebram apenas o passado, mas reivindicam explicitamente a sua continuidade; o seu ritual serve para difundir valores do grupo por meio do compartilhamento com os indivíduos, mediante a repetição e a invariância da informação, com evidente função mnemônica (CONNERTON, 1999, p. 52-66), viabilizada pela existência dos calendários, que permitem reunir e coordenar os sucessivos eventos por semelhança cronológica, como se fossem qualitativamente idênticos.

No caso da comemoração e tributos às vítimas, a sua forma será determinante para a maneira como serão lembradas, e que tipo de mensagem será perpetuada. Então é preciso encontrar meios adequados de efetivar o direito à memória dos mortos e desaparecidos, começando pela construção de uma narrativa verdadeira e suficiente, ainda que inconclusa, do seu paradeiro e razões do seu desaparecimento, e fixar espacialmente a memória individual e coletiva, numa verdadeira "batalha pela marca”, como refere Jelin (2009, p. 132), cujo sucesso ou fracasso depende do momento histórico.

Há diferentes maneiras de marcar lugares, como a criação de museus e monumentos, mas na construção da memória dos desaparecidos também é necessário criar um ritual, uma performance de palavras e gestos, capaz de produzir e reproduzir a versão que se quer preservar (SHAFIR, 2009, p. 154-155). A repetição desses ritos é um dos instrumentos institucionalizantes da memória, pois dota o acontecimento comemorativo de um sentido, e deve ser direcionada a uma finalidade específica, a celebrar um valor social.

A dor não é um valor, é uma experiência. As performances não devem cultivar a dor porque a rememoração será condenada a repetir indefinidamente o trauma, pois por meio delas não se corrige e nem se restitui o passado (SHAFIR, 2009, p. 160-161). No caso dos desaparecidos e mortos do conflito armado na Colômbia, buscar "vítimas" significa eleger a dor como valor de co-memoração 4 , ao passo que buscar "cidadãos” pode contribuir para educar a sociedade no sentido de fortalecer verdadeiramente a democracia.

Mesmo que essa busca não leve à monumentalização em sentido lato da memória dos

\footnotetext{
${ }^{4}$ Co-memorar significa "lembrar juntos”, e não possui necessariamente um caráter festivo.
} 
desaparecidos e dos sobreviventes, é necessário esclarecer o significado dessas pessoas para a memória coletiva, garantindo que sejam lembradas e celebradas adequadamente. Como bem ressalta Lira (2009, p. 69), só por meio da afirmação do que efetivamente aconteceu, do reconhecimento dos direitos violados e da punição dos responsáveis é possível realizar a reparação psicológica e moral das vítimas, que foram desacreditadas e estigmatizadas.

Entretanto, a criação de memórias individuais e coletivas é um processo contínuo, dinâmico, que pode até acirrar conflitos ao invés de minimizá-los, como bem adverte Campisi (2014, p. 69), correndo-se o risco de indevidamente criar uma preferência ou ranking entre vítimas, bem como entre suas narrativas.

h) Garantias de não repetição, para impedir a retomada do conflito e novas formas de violência.

Essas medidas de satisfação aparecem combinadas a medidas de reparação material (indenização, por exemplo), haja vista que apenas essas últimas não são suficientes, pois podem ser interpretadas como uma forma de comprar o silêncio e a aquiescência das vítimas, ou de privilegiar umas em detrimento de outras. Como bem destaca Campisi (2014, p. 66), as medidas de reparação relacionadas à memória individual e coletiva, à forma de lidar com o passado, não estão ligadas ao esquecimento, mas a trazer à luz fatos mediante a co-memoração, restaurando a dignidade das vítimas e prevenindo danos às futuras gerações. São menos uma forma de fechamento (closure) do passado e mais um processo de aperfeiçoamento, progresso e avanço.

O texto rejeitado já as previa - por exemplo, o acordo de cessar fogo para cessar a continuidade das violações, a criação de uma comissão da verdade -, porém foram incorporadas alterações, a partir do referendo, que reduziram a abrangência da anistia concedida aos membros das FARC, além de impor a obrigação de revelar as estruturas do tráfico e a doação do patrimônio da organização para indenizar as vítimas.

Sem dúvida, o texto aprovado traz importantes contribuições para realizar uma transição mais justa, na medida em que o seu objetivo é a inserção democrática dos cidadãos, considerando que a participação política é fundamental para a construção da paz, e que não é apenas uma decisão administrativa ou governamental, algo tornado mais evidente no ponto 2 do acordo.

Nessa parte pretende-se a efetivação de direitos políticos e garantias, especialmente quanto à liberdade de manifestação e participação, garantindo voz aos movimentos sociais, historicamente criminalizados, mudanças no sistema eleitoral, democratização dos meios de comunicação e a criação de um programa governamental que busque construir a reconciliação, a convivência e a prevenção da estigmatização. 
Tais medidas podem contribuir para explicitar a democracia como um valor a ser protegido e cultivado, cujo objetivo seria alcançado a partir da criação de um patrimônio democrático, composto por valores, símbolos, monumentos, ideais e práticas, que possa ser transmitido às futuras gerações, e com ele refundar o sentido de pertencimento e unidade nacionais (FOCARDI, 2009, p. 278; FONT, 2009, p. 382).

A questão passa a ser como criar laços intergeracionais na experiência comum da democracia, ou seja, como corporificar esse valor em um patrimônio que permita veicular, ensinar, repassar às futuras gerações o valor da democracia, para enraizar uma cultura específica de apoio e continuidade de instituições legítimas, pois a melhor garantia de estabilidade é a participação política do cidadão (DANTAS, 2015, p. 90-92).

A experiência negativa do conflito e a positiva da sua superação passam a constituir a herança cultural de um povo, que deve ser revertida em seu benefício. Cada geração tem o direito de se beneficiar da herança cultural, inseparavelmente acompanhado da obrigação de usar esse patrimônio de maneira tal que possa ser transmitido às futuras gerações nas mesmas condições (no worse) que receberam da geração anterior (CANÇADO TRINDADE, 1993, p. 297). Ou seja, tanto os Estados como os indivíduos, considerados individualmente, em grupo ou mesmo agrupados segundo um critério temporal (geração), têm o dever de transmitir a herança cultural, viabilizando o exercício do direito à memória (DANTAS, 2010, p. 71).

O patrimônio democrático, quaisquer que sejam os bens culturais que o compõe, deve ser capaz de demostrar o acúmulo das experiências individuais e coletivas que contribuem para estruturar um sistema baseado na defesa dos direitos fundamentais e valores consagrados na constituição, com uma finalidade ética e política, ainda que necessariamente histórica, de construção de uma sociedade melhor (INIESTA, 2009, p. 480).

A lição de não esquecer, de não permitir violações de direitos fundamentais, de não anistiar abusivamente, de não aceitar quebras da ordem jurídica considerada legítima e de defender as instituições responsáveis pela existência e continuidade do Estado deve ser aprendida e cotidianamente praticada.

\section{CONSIDERAÇÕES FINAIS}

O presente artigo trouxe uma breve reflexão sobre o dever de memória como um dos possíveis fatores que levaram ao resultado negativo no referendo à primeira proposta de acordo de paz proposto entre o governo colombiano e as FARC, que pode ser interpretado como uma rejeição 
às formas tradicionais de esquecimento que caracterizam as transições latino-americanas.

Algumas dessas estratégias de esquecimento foram identificadas na transição colombiana: o silêncio e minimização de conflitos, concessão de anistias e a busca da reconciliação nacional pela superação das “divergências” anteriores. O “não”, a despeito de dúvidas quanto à representatividade e legitimidade do resultado referendo, serviu para impulsionar uma maior discussão quanto ao texto final do acordo, que procurou atender à voz dissonante.

Se o legado da paz rejeitada foi esclarecer os fatos, estabelecer uma base melhor para o consenso, instaurar o diálogo e aprofundar a percepção da efetivação do direito à memória, à verdade e à justiça, o "não” se revela como um importante passo na consolidação da democracia e da paz verdadeira, duradoura e estável para a sociedade colombiana.

Entretanto, a reconciliação e a pacificação nacional são um processo que não se exaure em decisão administrativa ou legislativa, e muito menos no texto aprovado. Mesmo que seja executado à perfeição, o acordo de paz refletiu um momento específico da sociedade colombiana em lidar com o seu passado, e nada impede que no futuro esse mesmo passado seja revisado, ressignificado e reconstruído, com consequências e percepções diversas. As sucessivas gerações de colombianos, ligadas por laços de solidariedade intergeracional, serão as verdadeiras responsáveis pela construção de uma memória coletiva e de um patrimônio democrático que leve à superação dos efeitos traumáticos do conflito.

Em conclusão, afirma-se que o processo de negociação da cessação dos conflitos na Colômbia não é benéfico apenas para o país e seus cidadãos, mas também proporciona uma experiência e um conhecimento que podem vir a beneficiar outros povos. A maneira de entender, construir e aceitar uma paz possível, ainda que rejeitada preliminarmente, incorporando-se então as demandas de quem dela discordou, demonstra a necessidade democrática de se dar voz e compatibilizar os anseios de uma sociedade diversificada.

\section{REFERÊNCIAS}

BAEZA, Paz Rojas. Mental health disturbances caused by the absence of truth and justice. 2005. Disponível em: <https://goo.gl/Y3ghLm>. Acesso em: 31 jan. 2005.

CAMPISI, Maria Chiara. From a duty to remember to an obligation to memory? Memory as reparation in the jurisprudence of the Inter-American Court of Human Rights. International Journal of Conflict and Violence, v. 8(1), 2014, p. 61-74.

CANÇADO TRINDADE, Antônio Augusto. Direitos humanos e meio ambiente: paralelo dos sistemas de proteção internacional. Porto Alegre: Sergio Antonio Fabris Editor, 1993. 
CARRETERO, Mario. Documentos de identidade: a construção da memória histórica em um mundo globalizado. São Paulo: Artmed, 2010.

CENTRO NACIONAL DE MEMORIA HISTÓRICA (CNMH). El estado de sitio, las reclamaciones de las víctimas y el derecho a la justicia en la excepción (1985-1990). In: El derecho a la justicia como garantía de no repetición. Bogotá: CNMH, 2016, tomo 1, p. 15-52. Disponível em: $<$ https://goo.gl/6JdrDj>. Acesso em: 14 fev. 2017.

CONNERTON, Paul. Como as sociedades recordam. Oeiras: Celta, 1999.

CRENZEL, Emilio. Los derechos humanos y las políticas de la memoria. Reflexiones a partir de las experiencias de las comisiones de la verdad en Argentina y Chile. In: VINYES, Ricard (Ed.). El Estado y la memoria - Gobiernos e ciudadanos frente a los traumas de la historia. Buenos Aires: Del Nuevo Extremo, 2009, p. 357-367.

DANTAS, Fabiana Santos. A democracia como patrimônio: solidariedade intergeracional no processo transicional brasileiro. In: CAMPELLO, Livia Gaigher Bosio; PADILHA, Norma Sueli; MELEU, Marcelino. Direito ambiental e socioambientalismo I. Florianópolis: Conpedi, 2015.

DANTAS, Fabiana Santos. O Direito fundamental à memória como instrumento da transição democrática. In: SANTOS, Gustavo Ferreira; ARAÚJO, Marcelo Labanca Corrêa de; FELICIANO, Ivna Cavalcanti (Org.). Direito em dinâmica: 25 anos da Constituição de 1988. Recife: Instituto Frei Caneca, 2014.

DANTAS, Fabiana Santos. O direito fundamental à memória. Curitiba: Juruá, 2010.

FILLOUX, Jean-Claud. A memória. São Paulo: Difusão Européia do Livro, 1959.

FOCARDI, Filippo. El debate sobre la resistencia en Italia: legitimación política y memoria histórica de la Primera a la Segunda República. In: VINYES, Ricard (Ed.). El Estado y la memoria Gobiernos e ciudadanos frente a los traumas de la historia. Buenos Aires: Del Nuevo Extremo, 2009, p. 249-290.

FONT, Jordi. Contra la nostalgia (y a favor). El rescate de la memoria democrática como identidad civil. In: VINYES, Ricard (Ed.). El Estado y la memoria - Gobiernos e ciudadanos frente a los traumas de la historia. Buenos Aires: Del Nuevo Extremo, 2009, p. 371-392.

INIESTA, Alberto; GONZÁLEZ, Monserrat Iniesta. Patrimonio, ágora e ciudadanía: lugares para negociar memorias productivas. In: VINYES, Ricard (Ed.). El Estado y la memoria - Gobiernos e ciudadanos frente a los traumas de la historia. Buenos Aires: Del Nuevo Extremo, 2009, p. 467-498.

JELIN, Elizabeth ¿Quiénes? ¿cuando? ¿para qué?: actores e escenarios de las memorias. In: VINYES, Ricard (Ed.). El Estado y la memoria - Gobiernos e ciudadanos frente a los traumas de la historia. Buenos Aires: Del Nuevo Extremo, 2009, p. 117-150.

KAUFMAN, Susana. Lo legado y lo proprio: lazos familiares y transmisión de memorias. In: JELIN, Elizabeth; KAUFMAN, Susana G. (Comp.). Subjetividad y figuras de la memoria. Buenos Aires: Siglo XXI; Editora Iberoamericana, 2006, p. 47-71.

LECHNER, Norbert; GÜELL, Pedro. Construcción social de las memorias en la transicion chilena. 
In: JELIN, Elizabeth; KAUFMAN, Susana G. (Comp.). Subjetividad y figuras de la memoria. Buenos Aires: Siglo XXI; Editora Iberoamericana, 2006, p. 17-46.

LIRA, Elizabeth. Las resistencias de la memoria: olvidos jurídicos y memorias sociales. In: VINYES, Ricard (Ed.). El Estado y la memoria - Gobiernos e ciudadanos frente a los traumas de la historia. Buenos Aires: Del Nuevo Extremo, 2009, p. 67-115.

MARCOS, Ana. Voto evangélico é chave na vitória do 'não' no plebiscito da Colômbia. 13 out. 2016. Disponível em: <https://goo.gl/gPG296>. Acesso em: 13 fev. 2017.

MIÑARRO, Anna; MORANDI, Teresa. Trauma psíquico y transmisión intergeneracional. Efectos psíquicos de la Guerra del 36, la posguerra, la dictadura y la transición en los ciudadanos de Cataluña. In: VINYES, Ricard (Ed.). El Estado y la memoria - Gobiernos e ciudadanos frente a los traumas de la historia. Buenos Aires: Del Nuevo Extremo, 2009, p. 441-463.

NOITE e Neblina (Nuit et Bruillard). Direção: Alain Resnais. Documentário (França, 1955). Formato original: 1.33:1, fullscreen. Suporte: DVD, 32 minutos. Aurora DVD, 2006.

ORGANIZAÇÃO DAS NAÇÕES UNIDAS. Basic principles and guidelines on the right to a remedy and reparation for victims of gross violations of international human rights law and serious violations of international humanitarian law (Resolution 60/147 of 16 December 2005). Disponível em: <https://goo.gl/hN2D2L>. Acesso em: 17 fev. 2017.

PASTORIZA, Lila. Hablar de memorias en Argentina. In: VINYES, Ricard (Ed.). El Estado y la memoria - Gobiernos e ciudadanos frente a los traumas de la historia. Buenos Aires: Del Nuevo Extremo, 2009, p. 291-329.

PIOVESAN, Flávia; BICUDO, Hélio. Direito à verdade e à justiça? Folha de São Paulo, Tendências/Debates, 2 dez. 2006.

PLEBISCITO en Colombia: Gana el No con 50.21\%. Telesur, Noticias, América Latina. 2 octubre 2016. Disponível em: <https://goo.gl/K0uNrl>. Acesso em: 13 fev. 2017.

POLLAK, Michael. Memória, esquecimento, silêncio. Estudos Históricos, Rio de Janeiro, v. 2, n. 3, p. 3-15, 1989.

SHAFIR, Isabel Piper. Investigación y acción política en prácticas de memoria colectiva. In: VINYES, Ricard (Ed.). El Estado y la memoria - Gobiernos e ciudadanos frente a los traumas de la historia. Buenos Aires: Del Nuevo Extremo, 2009, p. 151-172.

VINYES, Ricard. La memoria del Estado. In: VINYES, Ricard (Ed.). El Estado y la memoria Gobiernos e ciudadanos frente a los traumas de la historia. Buenos Aires: Del Nuevo Extremo, 2009, p. 23-66.

WEINRICH, Harald. Lete - Arte e crítica do esquecimento. Rio de Janeiro: Civilização Brasileira, 2001. 
Fabiana Santos Dantas

Doutora em Direito Público pela Universidade Federal de Pernambuco - UFPE (2009). Procuradora federal, atuando no IPHAN, e professora no departamento de Direito Público Geral e Processual da UFPE. E-mail: fabiana.dantas@ufpe.br 